\title{
Influência do solvente no conteúdo total de polifenóis, antocianinas e atividade antioxidante de extratos de bagaço de uva (Vitis vinifera) variedades Tannat e Ancelota
}

\author{
Solvent Influence on total polyphenol content, anthocyanins, and antioxidant activity of grape (Vitis vinifera) \\ bagasse extracts from Tannat and Ancelota - different varieties of Vitis vinifera varieties
}

Ismael Ivan ROCKENBACH ${ }^{1 \star}$, Graciela Lessa da SILVA ${ }^{1}$, Eliseu RODRIGUES ${ }^{1}$, Eugênia Marta KUSKOSKI ${ }^{1}$, Roseane FETT ${ }^{1}$

\begin{abstract}
Resumo
Diferentes sistemas solventes foram aplicados para determinar a eficiência de extração de compostos com capacidade antioxidante em bagaço de uva, importante subproduto do processo de vinificação. Realizou-se a quantificação de compostos fenólicos totais, antocianinas totais e atividade antioxidante nos extratos de bagaço de uva Vitis vinifera das variedades Tannat e Ancelota, provenientes da região de Videira, Santa Catarina. A atividade antioxidante foi determinada pelos métodos ABTS, FRAP e $\beta$-caroteno/ácido linoléico. Conteúdos de compostos fenólicos totais em acetona 50 e 70\% foram maiores nas duas variedades, enquanto que os conteúdos de antocianinas totais extraídos em ambas as variedades foram maiores no solvente etanol em concentrações de 50 e $70 \%$. Pelo método ABTS, a atividade antioxidante foi maior nas concentrações de 50 e $70 \%$ de acetona para a variedade Tannat e 50 e $70 \%$ de acetona e etanol para a variedade Ancelota. Em relação ao poder redutor pelo método FRAP, este foi maior em solvente acetona $70 \%$ para as duas variedades. No ensaio do poder de inibição da oxidação, a adição de 100 e $200 \mu \mathrm{L}$ de extratos etanólicos a 50\% das variedades Tannat e Ancelota apresentou maior eficiência, sendo quase duas vezes superior aos extratos acetônicos testados.
\end{abstract}

Palavras-chave: subprodutos; extração; oxidação; poder redutor.

\begin{abstract}
Different solvent systems were applied in order to determine the extraction efficiency of compounds with antioxidant capacity from grape bagasse, an important by-product from wine production. The quantification of total phenolics, anthocyanins, and antioxidant activity was carried out in grape bagasse extracts of Tannat and Ancelota varieties from the region of Videira, state of Santa Catarina. The antioxidant activity was determined by ABTS, FRAP, and $\beta$-carotene/linoleic acid system methods. Extracts from acidified aqueous solutions of acetone and ethanol in different concentrations (v/v) showed higher yield in aqueous solutions of acetone 50 and $70 \%$ for Tannat variety and acetone/ethanol $50 \%$ for Ancelota variety, respectively. The total phenolic contents in acetone 50 and $70 \%$ were higher in both varieties while the anthocyanin contents in these varieties were higher in ethanol 50 and 70\%. The antioxidant activity was higher in acetone 50 and $70 \%$ for Tannat variety and acetone/ethanol 50 and 70\% for Ancelota variety by the ABTS method. Regarding the reduction power performed by the FRAP method, it was higher in acetone $70 \%$ in both varieties. During the oxidation inhibition power assay, the addition of 100 and $200 \mu \mathrm{L}$ of ethanolic extracts $50 \%$ of Tannat and Ancelota varieties showed higher efficiency since it was almost two times higher than acetonic extracts.

Keywords: byproducts; extraction; oxidation; reduction power.
\end{abstract}

\section{Introdução}

É de conhecimento científico o potencial antioxidante dos compostos fenólicos, atuando como redutores de oxigênio singleto, nas reações de oxidação lipídica e na quelação de metais. Apresentam uma ampla gama de propriedades farmacológicas, como antialergênicas, antiarteriogênicas, antiinflamatórias, antimicrobianas, antitrombóticas e também efeitos cardioprotetores e vasodilatadores (PUUPPONEN-PIMIÄ et al., 2001; MANACH; MAZUR; SCALBERT, 2005).

A uva é fonte de diversos compostos fenólicos em elevadas concentrações e os subprodutos da vinificação, em sua maioria, podem manter quantidades apreciáveis, principalmente de fenólicos, que pertencem ao grupo dos flavonóides. Os glicosídeos de flavonóis e as antocianinas estão entre os compostos fenólicos mais determinados e estudados nas uvas, por sua destacada atividade antioxidante e por suas propriedades antiinflamatórias e anticancerígenas (NEGRO; TOMMASI; MICELI, 2003; AMICO et al., 2004; SILVA; MATIAS; NUNES, 2005).

O processo de fabricação do vinho gera uma quantidade estimada de resíduo sólido de $20 \%$ do peso inicial (GÓMEZ-PLAZA; MIÑANO; LÓPEZ-ROCA, 2006). Alguns estudos a respeito dos subprodutos da vinificação focalizam principalmente a composição de polifenóis das sementes, que são muito ricas em flavonóis (YILMAZ; TOLEDO, 2004; GUENDEZ et al., 2005b). As sementes representam em torno

Recebido para publicação em 12/6/2007

Aceito para publicação em 11/1/2008 (002600)

${ }^{1}$ Centro de Ciências Agrárias, Química de Alimentos, Ciência e Tecnologia de Alimentos, Universidade Federal de Santa Catarina - UFSC, CEP 88034-001, Florianópolis - SC, Brasil,E-mail: ismael.rockenbach@gmail.com

${ }^{*}$ A quem a correspondência deve ser enviada 
de $15 \%$ do resíduo sólido produzido e contêm de 14 a $17 \%$ de óleo, o que depende da variedade da uva (GÖKTÜRK BAYDAR; AKKURT, 2001; LUQUE-RODRÍGUEZ; LUQUE DE CASTRO; PÉREZ-JUAN, 2005).

Outros estudos focalizam o potencial antioxidante do bagaço em sua totalidade, composto de sementes e das cascas (ALONSO et al., 2002; LOULI; RAGOUSSIS; MAGOULAS, 2004; KAMMERER et al., 2005; PINELO et al., 2005). Outras partes do conjunto da uva são rejeitadas durante o processo de vinificação, como os engaços, e recebem muito menos atenção, embora contenham uma quantidade importante de polifenóis (SOUQUET et al., 2000).

A recuperação de compostos antioxidantes dos desperdícios contínuos da indústria de vinho poderia representar um avanço significativo na manutenção do equilíbrio do meio ambiente, visto que nas vinícolas as grandes quantidades de resíduos gerados apresentam sérios problemas de armazenagem, de transformação, ou de eliminação, em termos ecológicos e econômicos. Esta situação explica o interesse crescente em explorar os subprodutos da vinificação (ALONSO et al., 2002).

Diversos métodos e sistemas de solventes vêm sendo usados para a extração de polifenóis de matérias vegetais (CHAVAN; SHAHIDI; NACZK, 2001), visando determinar a capacidade antioxidante (GOLI; BARZEGA; SAHARI, 2004; PRIOR; WU; SCHAICH, 2005). O tipo de solvente e a polaridade podem afetar a transferência de elétrons e de átomos de hidrogênio, que é aspecto-chave na medida da capacidade antioxidante. A presença de compostos não antioxidantes nas soluções testadas também pode afetar os resultados (PÉREZ-JIMÉNEZ; SAURA-CALIXTO, 2006). O rendimento da extração depende tanto do solvente utilizado (OU; HAMPSCH-WOODILL; PRIOR, 2001; GRAY et al., 2002; YU et al., 2002; SUN; HO, 2005; YILMAZ; TOLEDO, 2006) como do método aplicado, que pode ser baseado em mecanismos químicos diferentes. Além do rendimento, há grande variação na composição do extrato em função do sistema solvente utilizado (MOURE et al., 2001).

O objetivo deste estudo foi avaliar o conteúdo total de fenólicos, antocianinas e a capacidade antioxidante do extrato de bagaço de uva (Vitis vinifera) de duas variedades, Tannat e Ancelota, utilizando diferentes sistemas solventes.

\section{Material e métodos}

\subsection{Amostras}

Foram utilizadas amostras de bagaço das uvas tintas Vitis vinifera, var. Tannat e Ancelota, coletadas na região de Videira, Santa Catarina. As amostras são resultantes da safra de 2005/2006, sendo cedidas pela EPAGRI (Empresa de Pesquisa Agropecuária e Extensão Rural de Santa Catarina) de Videira, Santa Catarina. Tendo por objetivo preservar as propriedades gerais dos bagaços, os exemplares foram acondicionados em caixas isotérmicas contendo gelo e encaminhados imediatamente ao laboratório, onde foram armazenados à temperatura de $-18,0 \pm 0,2^{\circ} \mathrm{C}$ e posteriormente analisados.

\subsection{Métodos}

\section{Preparação dos extratos}

As amostras de bagaço de uva das variedades Tannat e Ancelota foram submetidas a tratamento térmico em estufa de ar circulante a $80^{\circ} \mathrm{C}$, num período de 10 minutos, para inativação enzimática (VALDERRAMA; MARANFONI; CLEMENTE, 2001; TROIANI; TROPIANI; CLEMENTE, 2003). Posteriormente, foram secas em estufa de ar circulante, à temperatura de $50{ }^{\circ} \mathrm{C}$ por 24 horas. Após resfriamento em dessecador, as amostras foram trituradas (60 mesh) e desengorduradas em extrator Soxhlet, utilizando solvente hexano, durante 6 horas a $60^{\circ} \mathrm{C}$. $\mathrm{O}$ resíduo do bagaço foi submetido à extração com diferentes sistemas solventes. Os extratos foram preparados com 2,5 g de material seco desengordurado, utilizando, como solventes extratores, as seguintes soluções aquosas: etanol e acetona a 0 , $30,50,70$ e $100 \%$ (v/v), acidificados com $\mathrm{HCl}$ a $0,1 \%$. A extração $(3 \times 25 \mathrm{~mL})$ foi procedida sob agitação mecânica e ao abrigo da luz no intervalo de 2 horas, sendo posteriormente filtrados em papel filtro Whatman $n^{\circ} 1$ e transferidos para balão volumétrico com volume final ajustado para $50 \mathrm{~mL}$.

\section{Determinação de fenólicos totais}

O conteúdo total de polifenóis em cada extrato foi determinado espectrofotometricamente de acordo com o método de Folin-Ciocalteau (ROSSI; SINGLETON, 1965), com a leitura da absorbância em $764 \mathrm{~nm}$, e os resultados expressos em gramas de equivalentes a ácido gálico (GAE) por $100 \mathrm{~g}$ de extrato seco. Uma alíquota de $0,1 \mathrm{~mL}$ da amostra diluída foi misturada com 0,5 $\mathrm{mL}$ do reagente de Folin-Ciocalteau e 1,5 mL de carbonato de sódio $20 \%$ em balão volumétrico de $10 \mathrm{~mL}$, completando-se o volume com água destilada. A concentração do conteúdo de fenólicos totais foi medida após 2 horas de repouso da mistura e seu valor comparado com o do padrão de ácido gálico.

\section{Determinação do conteúdo total de antocianinas}

A análise do conteúdo total de antocianinas foi realizada seguindo-se o método de diferença de pH (GIUSTI; WROLSTAD, 2001). Os extratos foram diluídos para que a amostra atingisse uma absorbância entre 0,100 e 1,200 no comprimento de onda de $520 \mathrm{~nm}$. Para uma alíquota de $0,2 \mathrm{~mL}$ de amostra diluída, foram adicionados $1,8 \mathrm{~mL}$ da solução de cloreto de potássio ( $\mathrm{pH}$ 1) em tubos de ensaio, homogeneizados e armazenados por 10 minutos em ausência de luz, tendo sido realizado procedimento equivalente com solução de acetato de sódio ( $\mathrm{pH} 4,5$ ). A absorbância foi medida no comprimento de onda máximo e em $700 \mathrm{~nm}$, e o branco feito com água destilada. Os resultados foram expressos como concentração de pigmentos monoméricos (mg.100 $\left.\mathrm{g}^{-1}\right)$ e expressos em equivalente à malvidina-3glicosídeo $(\varepsilon=29500, \mathrm{PM}=562,5)$.

\section{Determinação da capacidade antioxidante - Método ABTS ${ }^{+}$}

Para determinar a atividade antioxidante, utilizou-se o método descrito por Re et al. (1999). O radical ABTS ${ }^{\bullet+}$ foi formado pela reação de 2,45 $\mathrm{mM}$ de persulfato de potássio com 7 
mM de 2,2'azino-bis-(3-etilbenzotiazolin 6-ácido sulfônico), armazenado no escuro, à temperatura ambiente, durante 16 horas. Uma vez formado, o radical $\mathrm{ABTS}^{\bullet+}$ foi diluído em etanol até obter-se uma medida de absorbância de $0,70( \pm 0,02)$ em comprimento de onda de $754 \mathrm{~nm}$, a uma temperatura de equilíbrio de $30^{\circ} \mathrm{C}$ (KUSKOSKI et al., 2004). A absorbância foi medida em espectrofotômetro modelo Hewlett-Packard 8425A, no tempo de 7 minutos após a adição da amostra. A capacidade antioxidante total da amostra foi calculada em relação à atividade do antioxidante sintético Trolox, nas mesmas condições, e os resultados foram expressos em $\mu \mathrm{Mol}$ TEAC.g ${ }^{-1}$ (atividade antioxidante equivalente ao Trolox) (RICE-EVANS; MILLER; PAGANGA, 1996).

\section{Determinação do poder redutor - Método FRAP}

Utilizou-se o método descrito por Benzie e Strain (1996), com modificações de Arnous, Makris e Kefalas (2002). Este se baseia na medida direta da habilidade dos antioxidantes (redutores) da amostra em reduzirem, em meio ácido $(\mathrm{pH} 3,6)$, o complexo $\mathrm{Fe}^{3+}$ /tripiridiltriazina (TPTZ), para formar $\mathrm{Fe}^{2+}$, de intensa cor azul e absorção máxima a $593 \mathrm{~nm}$. As amostras de extrato do bagaço de uva foram diluídas em água destilada e foi acrescentado um volume de $0,1 \mathrm{~mL}$ de cloreto férrico $3 \mathrm{mM}$ (em ácido cítrico $5 \mathrm{mM}$ ) a $0,1 \mathrm{~mL}$ da amostra. A mistura foi mantida em banho-maria a $37^{\circ} \mathrm{C}$ por 30 minutos. Após este tempo, adicionou-se 1,8 mL de solução TPTZ (2,4,6-tri(2-piridil)-striazina) $1 \mathrm{mM}$ em $\mathrm{HCl}$ 0,05 M. Transcorridos 10 minutos, a absorbância foi medida em comprimento de onda de $620 \mathrm{~nm}$. $O$ valor de $P_{R}$ foi calculado de acordo com a curva de calibração previamente preparada, sendo os resultados expressos em $\mu \mathrm{Mol}$ TEAC.g ${ }^{-1}$ (atividade antioxidante equivalente ao Trolox).

\section{Determinação da capacidade antioxidante - Sistema de co-oxidação do $\beta$-caroteno/ácido linoléico}

A avaliação da atividade antioxidante foi realizada em meio emulsionado, através da técnica de co-oxidação de substratos, segundo Marco (1968) e modificada por Miller (1971). O método colorimétrico é realizado em comprimento de onda de $470 \mathrm{~nm}$ e baseia-se na leitura referente à descoloração da solução preparada de $\beta$-caroteno e ácido linoléico, em meio aquoso.

Uma alíquota de $20 \mu \mathrm{L}$ da solução de $\beta$-caroteno (20 mg. $\mathrm{mL}^{-1}$ em clorofórmio) foi colocada em um frasco erlenmeyer de $250 \mathrm{~mL}$ com $40 \mu \mathrm{L}$ de ácido linoléico, $1 \mathrm{~mL}$ de clorofórmio e $20 \mathrm{mg}$ de Tween 40 . O clorofórmio foi completamente evaporado com nitrogênio. Ao erlenmeyer foram adicionados $150 \mathrm{~mL}$ de água deionizada (previamente submetida a tratamento com atmosfera de oxigênio, durante 30 minutos). A emulsão apresentou-se límpida e sua absorbância foi ajustada entre 0,7 a $0,6 \mathrm{~nm}$ a $470 \mathrm{~nm}$. Diferentes alíquotas dos extratos a 100 ppm (50, 100 e $200 \mu \mathrm{L})$ foram comparadas ao controle (sem antioxidante) e ao BHT (butil hidroxitolueno), utilizado como antioxidante padrão. Além disso, o efeito sinérgico foi avaliado utilizando-se misturas das amostras com BHT nas mesmas concentrações do extrato puro. Uma leitura inicial da absorbância foi feita imediatamente após a adição das amostras e do padrão ao sistema visando à determinação do tempo zero. Posteriormente, a absorbância foi monitorada a cada 15 minutos, durante o período de 2 horas. As cubetas foram mantidas em banho-maria a $50{ }^{\circ} \mathrm{C}$ durante as leituras.

A capacidade antioxidante foi calculada em termos de percentual de inibição.

\subsection{Análise estatística}

A análise dos dados foi realizada pela aplicação da ANOVA e o teste Tukey visando identificar diferenças significativas entre as médias, usando o software Statistica ${ }^{\varpi}$ 6.0. O nível de significância considerado para a diferença entre as médias foi de $5 \%$ $(\mathrm{p}<0,05)$. Todas as análises foram realizadas em triplicata e os resultados apresentados como média \pm desvio padrão.

\section{Resultados e discussão}

\subsection{Compostos fenólicos totais}

Os conteúdos de fenólicos totais extraídos com acetona e etanol nas diferentes concentrações estão indicados na Tabela 1. Os valores obtidos na extração com os sistemas solventes acetona 50 e $70 \%(\mathrm{v} / \mathrm{v})$ apresentaram maior conteúdo fenólico para as duas variedades de uva analisadas: 7,95 e 7,56 g GAE. $100 \mathrm{~g}^{-1} \mathrm{em}$ peso seco para a variedade Ancelota e 6,59 e 6,90 g GAE. $100 \mathrm{~g}^{-1}$ em peso seco para a variedade Tannat. Assim, as características físico-químicas destes sistemas solventes assemelham-se em maior grau às características da maioria dos compostos fenólicos presentes nas amostras avaliadas. Não houve diferença significativa entre as concentrações de 50 e $70 \%$ (v/v) em cada variedade estudada $(\mathrm{p}<0,05)$. Esses resultados estão de acordo com o estudo feito por Yilmaz e Toledo (2006), que relataram que misturas aquosas de acetona a 50 e $75 \%$ (v/v) foram mais eficientes na extração de constituintes fenólicos em semente de uva que os sistemas etanol 60\% e metanol 70\% (v/v).

Em uma recente pesquisa desenvolvida por Llobera e Cañellas (2007), com o bagaço de uvas tintas variedade "Manto Negro" (Vitis vinifera), os teores médios de compostos fenólicos extraídos seqüencialmente com metanol a $50 \%$ e acetona a $70 \%$ (v/v) oscilaram entre 2,63 e 11,6 g GAE. $100 \mathrm{~g}^{-1}$ em peso seco. Negro, Tommasi e Miceli (2003), estudando os resíduos da vinificação de uva da variedade "Negro amaro" na extração

Tabela 1. Compostos fenólicos totais de extratos de bagaço de uva (g GAE.100 g-1 peso seco).

\begin{tabular}{lcc}
\hline Solventes usados na extração & Ancelota & Tannat \\
\hline Água & $1,48 \pm 0,03^{\mathrm{a}}$ & $1,50 \pm 0,13^{\mathrm{a}}$ \\
Etanol 30\% & $5,41 \pm 0,02^{\mathrm{c}, \mathrm{d}}$ & $3,96 \pm 0,22^{\mathrm{b}}$ \\
Etanol 50\% & $7,32 \pm 0,31^{\mathrm{e}}$ & $5,84 \pm 0,14^{\mathrm{c}}$ \\
Etanol 70\% & $5,86 \pm 0,12^{\mathrm{d}}$ & $5,59 \pm 0,06^{\mathrm{c}}$ \\
Etanol 100\% & $2,73 \pm 0,02^{\mathrm{b}}$ & $3,73 \pm 0,02^{\mathrm{b}}$ \\
Acetona 30\% & $5,22 \pm 0,10^{\mathrm{c}}$ & $3,63 \pm 0,04^{\mathrm{b}}$ \\
Acetona 50\% & $7,95 \pm 0,25^{\mathrm{f}}$ & $6,59 \pm 0,12^{\mathrm{d}}$ \\
Acetona 70\% & $7,56 \pm 0,06^{\mathrm{e}} \mathrm{f}$ & $6,90 \pm 0,04^{\mathrm{d}}$ \\
Acetona 100\% & $1,82 \pm 0,23^{\mathrm{a}}$ & $1,32 \pm 0,16^{\mathrm{a}}$ \\
\hline
\end{tabular}

*Valores expressos como média \pm desvio padrão; e letras diferentes na mesma coluna apresentam diferença estatística entre si (Tukey HSD, $\mathrm{p}<0,05$ ). 
com etanol a $80 \%(\mathrm{v} / \mathrm{v})$ acidificado, encontraram conteúdos de compostos fenólicos de 3,33, 8,58 e 4,19 g GAE. $100 \mathrm{~g}^{-1}$ em peso seco na casca, semente e bagaço, respectivamente. Göktürk Baydar, Özkan e Sagdiç (2004), também estudando sementes e bagaço de uva, obtiveram 4,54 g GAE. $100 \mathrm{~g}^{-1} \mathrm{em}$ peso seco de compostos fenólicos totais em bagaço de uva utilizando acetato de etila:metanol:água (60:30:10) como sistema solvente e 2,95 g GAE. $100 \mathrm{~g}^{-1}$ com sistema solvente etanol a 95\% (v/v).

Diversos autores concluíram que não é uma tarefa fácil encontrar um método único que seja adequado para a análise de um grupo diverso de fenólicos devido à diversidade das estruturas químicas e variação de sensibilidade dos compostos às condições de extração (ANTOLOVICH et al., 2000). Os teores de compostos fenólicos presentes no bagaço de uva representam uma grande variedade de compostos, incluindo os flavonóides. Entre estes, destacam-se as antocianinas (ORAK, 2007). Kammerer et al. (2004) caracterizaram os compostos fenólicos de 14 diferentes amostras de bagaço de uva utilizando metanol acidificado como solvente extrator, sendo identificados 13 tipos de antocianinas, 11 ácidos fenólicos, 13 catequinas e flavonóis e 2 estilbenos.

\subsection{Antocianinas totais}

As antocianinas estão localizadas nas células próximas à superfície das plantas e são facilmente extraídas de materiais vegetais por solventes orgânicos. Tradicionalmente, soluções acidificadas de metanol, etanol, acetona, água e misturas de acetona/metanol/água têm sido usadas para a extração de antocianinas (JU; HOWARD, 2003).

Em nosso estudo utilizando acetona e etanol como sistemas solventes, os extratos do bagaço da uva apresentaram concentrações de antocianinas mais elevadas em meio hidroalcoólico: 1,93 g. $100 \mathrm{~g}^{-1}$ em peso seco na concentração de $70 \%$ e 1,95 g.100 $\mathrm{g}^{-1}$ em peso seco na concentração de $50 \%$ para a variedade Ancelota; e 0,77 g.100 g $\mathrm{g}^{-1}$ nas concentrações de 70 e $50 \%$ para a variedade Tannat (Tabela 2). Não houve diferença significativa entre as concentrações de 50 e $70 \%$ (v/v) em cada variedade estudada $(\mathrm{p}<0,05)$. Esses teores foram mais de duas vezes superiores aos teores obtidos com o sistema solvente acetona para as duas variedades avaliadas. Esta maior eficiência

Tabela 2. Antocianinas totais de extratos de bagaço de $\mathrm{uva}^{\star}\left(\mathrm{g} .100 \mathrm{~g}^{-1}\right.$ peso seco) ${ }^{1}$.

\begin{tabular}{ccc}
\hline Solventes usados na extração & Ancelota & Tannat \\
\hline Água & $0,13 \pm 0,02^{\mathrm{a}}$ & $0,04 \pm 0,00^{\mathrm{a}, \mathrm{b}}$ \\
Etanol 30\% & $1,30 \pm 0,04^{\mathrm{e}}$ & $0,50 \pm 0,03^{\mathrm{d}}$ \\
Etanol 50\% & $1,95 \pm 0,02^{\mathrm{f}}$ & $0,77 \pm 0,02^{\mathrm{e}}$ \\
Etanol 70\% & $1,93 \pm 0,06^{\mathrm{f}}$ & $0,77 \pm 0,03^{\mathrm{e}}$ \\
Etanol 100\% & $0,42 \pm 0,00^{\mathrm{c}}$ & $0,14 \pm 0,03^{\mathrm{b}, \mathrm{c}}$ \\
Acetona 30\% & $0,83 \pm 0,07^{\mathrm{d}}$ & $0,19 \pm 0,00^{\mathrm{c}}$ \\
Acetona 50\% & $0,50 \pm 0,03^{\mathrm{c}}$ & $0,37 \pm 0,01^{\mathrm{d}}$ \\
Acetona 70\% & $0,30 \pm 0,00^{\mathrm{b}}$ & $0,22 \pm 0,04^{\mathrm{c}}$ \\
Acetona 100\% & nd & nd \\
\hline
\end{tabular}

*Valores expressos como média \pm desvio padrão; letras diferentes na mesma coluna apresentam diferença estatística entre si (Tukey HSD, p < 0,05); nd = não detectado; e ${ }^{1}$ equivalente a malvidina-3-glicosídeo. na extração justifica a utilização, em diversos trabalhos, dos solventes hidroalcoólicos metanol e etanol em meio acidificado para a extração de antocianinas de resíduos do processo de vinificação.

Concentrações similares às encontradas em nosso estudo foram obtidas em recente trabalho publicado pelos pesquisadores Ruberto et al. (2007), que relataram extrair do bagaço de diferentes cultivares de uva, usando solvente metanol acidificado, valores médios de antocianinas totais na faixa de 0,38 a 2,9 g.100 g $\mathrm{g}^{-1}$ em peso seco. Negro, Tommasi e Miceli (2003) encontraram conteúdos de antocianinas totais de 0,98 g (equivalente a malvidina). $100 \mathrm{~g}^{-1} \mathrm{em}$ peso seco.

Entre outras funções, as antocianinas são contribuintes para as propriedades antioxidantes de alimentos (EINBOND et al., 2004). Segundo Gómez-Plaza, Miñano e López-Roca (2006), água e solventes hidroalcoólicos são preferidos quando o objetivo é obter corantes ou produtos antioxidantes para a indústria de alimentos.

\subsection{Atividade antioxidante e poder redutor}

A atividade antioxidante e o poder redutor para os extratos da variedade Ancelota e Tannat são apresentados na Tabela 3. A variação da atividade antioxidante foi expressiva em relação às concentrações de solventes utilizadas no experimento. Níveis de atividade antioxidante mais elevados para a variedade Tannat são observados nos extratos obtidos com solvente acetona nas concentrações de 50 e 70\% (v/v), de 466,4 e 476,2 $\mu \mathrm{Mol}$ TEAC. ${ }^{-1}$ respectivamente, sem diferença significativa entre si $(\mathrm{p}<0,05)$. Para a variedade Ancelota, os maiores valores de atividade antioxidante foram obtidos com solvente nas concentrações de 50 e $70 \%$ (v/v), de 400,7 e 389,9 $\mu \mathrm{Mol} \mathrm{TEAC.g^{-1 }}$

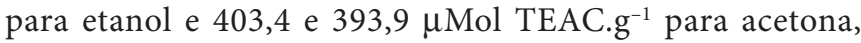
respectivamente, sem diferença significativa entre todos esses tratamentos $(\mathrm{p}<0,05)$.

A atividade antioxidante pode depender de vários fatores, incluindo as propriedades coloidais dos substratos, as condições e etapas de oxidação, a formação e estabilidade dos radicais, assim como a possível localização dos antioxidantes e estabilidade em distintas fases do processamento nos alimentos. Como descrevem Pérez-Jiménez e Saura-Calixto (2006), as diferenças observadas na atividade antioxidante, quando são utilizados diferentes solventes extratores, podem ser maiores se a amostra analisada for um alimento, visto que representa uma matriz complexa de diferentes componentes, que podem estabelecer, entre si e com os solventes, inúmeras e diferentes interações. Esses autores encontraram diferenças significativas na atividade antioxidante pelo método ABTS, influenciadas pela polaridade e pelo $\mathrm{pH}$ do solvente, com valores maiores em solventes mais polares e pHs maiores. Utilizando-se o método ABTS em nosso estudo, o coeficiente de regressão $r^{2}$ entre o conteúdo de fenólicos totais e a atividade antioxidante foi de 0,9199 e 0,9817 para as variedades Ancelota e Tannat, respectivamente. Esses valores confirmam os dados apresentados por diversos estudos, mostrando que a capacidade antioxidante é dependente do teor de compostos fenólicos presentes (ALONSO et al., 2002; GUENDEZ et al., 2005a; GÓMEZ-PLAZA; MIÑANO; 
LÓPEZ-ROCA, 2006; THAIPONG et al., 2006; MAKRIS; BOSKOU; ANDRIKOPOULOS, 2007).

Em estudo realizado por Pastrana-Bonilla et al. (2003), foram encontrados valores semelhantes aos de nosso estudo para a atividade antioxidante média, sendo de $326,3 \mu \mathrm{Mol} \mathrm{TEAC.g^{-1 }}$ em peso fresco para extratos metanólicos $(80 \%$ em $6 \mathrm{~N} \mathrm{HCl})$ de sementes de uva de diferentes variedades, pelo método ABTS (leitura em 6 minutos).

Os maiores valores de poder redutor obtidos pelo método FRAP foram de 746,7 e 684,7 $\mu \mathrm{Mol} \mathrm{TEAC.g^{-1 }}$ em solvente acetona a $70 \%(\mathrm{v} / \mathrm{v})$ para as variedades Ancelota e Tannat, respectivamente. No estudo realizado por Pulido, Bravo e Saura-Calixto (2000), observou-se que a utilização de diferentes solventes influencia o poder redutor da amostra a ser analisada. Segundo esses autores, a eficiência antioxidante determinada pelo método FRAP depende do potencial redox dos compostos analisados, caracterizado pela complexidade de suas moléculas. O coeficiente de regressão $\mathrm{r}^{2}$ entre o conteúdo de fenólicos totais e poder redutor foi de 0,951 e 0,9805 para Ancelota e Tannat, respectivamente, indicando a significativa relação entre esses parâmetros.

Em estudo realizado por Shui e Leong (2006), o valor de FRAP encontrado em resíduo de carambola foi de $510,3 \mu \mathrm{Mol}_{\mathrm{g}} \mathrm{g}^{-1}$ em peso seco. No estudo de Guo et al. (2003) com diversos tipos de frutas, o poder redutor de uva tinta foi equivalente a $670,5 \mu \mathrm{Mol.g}{ }^{-1}$ em peso fresco.

\subsection{Poder de inibição da oxidação}

Os extratos de bagaço de uva das variedades Ancelota e Tannat de concentração $50 \%$ (v/v) também foram testados pelo ensaio da inibição da oxidação de substratos $\beta$-caroteno/ácido linoléico (Tabela 4). Os extratos etanólicos apresentaram me- lhor percentual de inibição da oxidação, com 55,77 e 53,29\% na adição de $200 \mu \mathrm{L}$ dos extratos das variedades Tannat e Ancelota, respectivamente. Na seqüência, a adição de $100 \mu \mathrm{L}$ dos extratos etanólicos apresentou 40,35 e 42,98\% de inibição da oxidação, também para Tannat e Ancelota, respectivamente. Os extratos obtidos com acetona apresentaram poder de inibição da oxidação menor, aproximadamente metade do percentual obtido com adição de $200 \mu \mathrm{L}$ dos extratos etanólicos. Esses valores foram de 24,29 e 29,62\% para Tannat e Ancelota, respectivamente, na adição de $200 \mu \mathrm{L}$. Isto demonstra que, para os extratos analisados, o sistema solvente extrator influenciou a composição de substâncias com capacidade antioxidante presentes. Jayaprakasha, Singh e Sakariah (2001), utilizando diferentes sistemas solventes em extratos de semente de uva, obtiveram 89,3\% de inibição com acetato de etila em meio aquoso (proporção 17:3). Negro, Tommasi e Miceli (2003) relataram 73,50\% de inibição da oxidação na utilização de $200 \mu \mathrm{L}$ de extrato de bagaço de uva de concentração fenólica de 80 ppm.

O BHT apresentou maior eficiência em comparação com os extratos analisados. Observa-se que a mistura de BHT e extrato produziu efeito sinérgico, mantendo os percentuais de inibição semelhantes aos obtidos com o antioxidante sintético aplicado isoladamente, uma vez que a inibição obtida pelos extratos foi menos expressiva.

\section{Conclusões}

Os resultados deste trabalho demonstram que o sistema solvente utilizado na extração de bagaço de uva influencia diretamente os conteúdos de fenólicos totais, antocianinas e atividade antioxidante dos extratos. Compostos fenólicos totais foram mais bem extraídos em solvente acetona (50 e 70\%),

Tabela 3. Atividade antioxidante e Poder Redutor $\left(\mu \mathrm{Mol.g}^{-1}\right)$ em peso seco de extratos de bagaço de uva*

\begin{tabular}{lcccc}
\hline Amostras & \multicolumn{3}{c}{ Ancelota } & Tannat \\
\cline { 2 - 5 } & ABTS (TEAC) & FRAP (TEAC) & ABTS (TEAC) & FRAP (TEAC) \\
\hline Água & $66,1 \pm 0,9^{\mathrm{b}}$ & $218,7 \pm 1,2^{\mathrm{b}}$ & $37,1 \pm 1,0^{\mathrm{a}}$ & $201,7 \pm 2,3^{\mathrm{a}}$ \\
Etanol 30\% & $293,5 \pm 0,1^{\mathrm{d}}$ & $515,1 \pm 2,3^{\mathrm{d}}$ & $234,3 \pm 1,5^{\mathrm{b}}$ & $384,1 \pm 5,5^{\mathrm{b}}$ \\
Etanol 50\% & $400,7 \pm 4,2^{\mathrm{f}}$ & $686,4 \pm 3,7^{\mathrm{f}}$ & $341,5 \pm 3,5^{\mathrm{c}}$ & $531,7 \pm 3,7^{\mathrm{c}}$ \\
Etanol 70\% & $389,9 \pm 3,8^{\mathrm{f}}$ & $671,1 \pm 5,7^{\mathrm{f}}$ & $398,1 \pm 2,8^{\mathrm{d}}$ & $592,4 \pm 6,3^{\mathrm{d}}$ \\
Etanol 100\% & $158,8 \pm 2,3^{\mathrm{c}}$ & $334,1 \pm 4,7^{\mathrm{c}}$ & $226,2 \pm 2,6^{\mathrm{b}}$ & $395,1 \pm 5,7^{\mathrm{b}}$ \\
Acetona 30\% & $338,2 \pm 1,8^{\mathrm{e}}$ & $565,7 \pm 4,3^{\mathrm{e}}$ & $223,1 \pm 3,8^{\mathrm{b}}$ & $381,1 \pm 2,3^{\mathrm{b}}$ \\
Acetona 50\% & $403,4 \pm 3,4^{\mathrm{f}}$ & $710,1 \pm 6,7^{\mathrm{g}}$ & $466,4 \pm 2,2^{\mathrm{e}}$ & $647,7 \pm 6,3^{\mathrm{e}}$ \\
Acetona 70\% & $393,9 \pm 0,8^{\mathrm{f}}$ & $746,7 \pm 1,3^{\mathrm{h}}$ & $476,2 \pm 3,9^{\mathrm{e}}$ & $684,7 \pm 4,7^{\mathrm{f}}$ \\
Acetona 100\% & $17,2 \pm 0,4^{\mathrm{a}}$ & $164,4 \pm 1,7^{\mathrm{a}}$ & $48,2 \pm 1,3^{\mathrm{a}}$ & $204,1 \pm 1,7^{\mathrm{a}}$ \\
\hline
\end{tabular}

*Valores expressos como média \pm desvio padrão; e letras diferentes na mesma coluna apresentam diferença estatística entre si (Tukey HSD, $\mathrm{p}<0,05$ ).

Tabela 4. Percentual de inibição da oxidação pelo sistema de co-oxidação de substratos $\beta$-caroteno/ácido linoléico*.

\begin{tabular}{|c|c|c|c|c|c|c|c|c|c|}
\hline \multirow[t]{2}{*}{ Extratos } & \multicolumn{3}{|c|}{ Extrato } & \multicolumn{3}{|c|}{ BHT } & \multicolumn{3}{|c|}{ BHT + Extrato } \\
\hline & $50 \mu \mathrm{L}$ & $100 \mu \mathrm{L}$ & $200 \mu \mathrm{L}$ & $50 \mu \mathrm{L}$ & $100 \mu \mathrm{L}$ & $200 \mu \mathrm{L}$ & $25 / 25$ & $50 / 50$ & $100 / 100$ \\
\hline EtT & $13,17 \pm 1,54$ & $40,35 \pm 0,12$ & $55,77 \pm 0,80$ & $83,17 \pm 1,74$ & $89,33 \pm 2,38$ & $94,88 \pm 0,87$ & $72,10 \pm 0,59$ & $82,92 \pm 2,44$ & $91,89 \pm 1,18$ \\
\hline AcT & $13,22 \pm 1,18$ & $23,68 \pm 3,61$ & $24,29 \pm 2,25$ & $85,41 \pm 0,69$ & $95,52 \pm 1,70$ & $99,00 \pm 1,47$ & $62,62 \pm 6,32$ & $84,94 \pm 1,41$ & $91,28 \pm 1,05$ \\
\hline EtA & $7,63 \pm 2,02$ & $42,98 \pm 5,06$ & $53,29 \pm 2,39$ & $81,51 \pm 1,30$ & $88,93 \pm 1,32$ & $97,93 \pm 2,60$ & $62,12 \pm 0,32$ & $82,81 \pm 2,11$ & $89,65 \pm 0,93$ \\
\hline AcA & $6,11 \pm 2,16$ & $15,49 \pm 1,86$ & $29,62 \pm 3,42$ & $84,99 \pm 0,45$ & $91,35 \pm 0,58$ & $92,95 \pm 1,95$ & $66,02 \pm 0,96$ & $79,88 \pm 2,41$ & $89,25 \pm 0,54$ \\
\hline
\end{tabular}

EtT = extrato etanólico Tannat; EtA = extrato etanólico Ancelota; AcT = extrato acetônico Tannat; AcA = extrato acetônico Ancelota; e *alores expressos como média \pm desvio padrão. 
enquanto que as antocianinas foram mais bem extraídas em solvente etanol (50 e 70\%).

Para obtenção de dados ainda mais conclusivos, devem ser realizados trabalhos posteriores com outros cultivares difundidos no setor vitivinícola brasileiro e outros solventes indicados na literatura.

\section{Agradecimentos}

Ao $\mathrm{CNPq} /$ Capes pelo auxílio financeiro, e à EPAGRI (Empresa Catarinense de Pesquisa Agropecuária) de Videira, Estado de Santa Catarina, pelo fornecimento das amostras.

\section{Referências bibliográficas}

ALONSO, A. M. et al. Determination of antioxidant activity of wine byproducts and its correlation with polyphenolic content. Journal of Agricultural and Food Chemistry, v. 50, n. 21, p. 5832-5836, 2002.

AMICO, V. et al. Constituents of grape pomace from the Sicilian cultivar 'Nerello Mascalese'. Food Chemistry, v. 88, n. 4, p. 599-607, 2004.

ANTOLOVICH, M. et al. Sample preparation in the determination of phenolic compounds in fruits. Critical Review. Analyst, v. 125, p. 989-1009, 2000.

ARNOUS, A.; MAKRIS, D.; KEFALAS, P. Correlation of pigment and flavanol content with antioxidant properties in selected aged regional wines from Greece. Journal of Food Composition and Analysis, v. 15, n. 6, p. 655-665, 2002.

BENZIE, I. F. F.; STRAIN, J. J. The ferric reducing ability of plasma (FRAP) as a measure of antioxidant power: The FRAP assay. Analytical Biochemistry, v. 239, n. 1, p. 70-76, 1996.

CHAVAN, U. D.; SHAHIDI, F.; NACZK, M. Extraction of condensed tannins from beach pea (Lathyrus maritimus L.) as affected by different solvents. Food Chemistry, v. 75, n. 4, p. 509-512, 2001.

DUMON, M. C. Recherches analytiques sur les picnogenols. France, 1990, These - (pour le Doctorat d' Etat des Siences pharmaceutique), Universite de Bordeaux II.

EINBOND, L. et al. Anthocyanin antioxidant from edible fruits. Food Chemistry, v. 84, n. 1, p. 23-28, 2004.

GIUSTI, M. M.; WROLSTAD, R. E. Anthocyanins. Characterization and Measurement with UV-Visible Spectroscopy. In: Wrolstad, R. E. (Ed.). Current Protocols in Food Analytical Chemistry. New York: John Wiley \& Sons, 2001. Unit. F1.2.1-13.

GÖKTÜRK BAYDAR, N.; AKKURT, M. Oil content and oil quality properties of some grape seeds. Turkish Journal of Agriculture and Forestry, v. 25, p. 163-168, 2001.

GÖKTÜRK BAYDAR, N.; ÖZKAN, G.; SAGDIÇ, O. Total phenolic contents and antibacterial activities of grape (Vitis vinifera L.) extracts. Food Control, v. 15, n. 5, p. 335-339, 2004.

GOLI, A. H.; BARZEGAR, M.; SAHARI, M. A. Antioxidant activity and total phenolic compounds of pistachio (Pistachia vera) hull extracts. Food Chemistry, v. 92, n. 3, p. 521-525, 2004.

GÓMEZ-PLAZA, E.; MIÑANO, A.; LÓPEZ-ROCA, J. M. Comparison of chromatic properties, stability and antioxidant capacity of anthocyanin-based aqueous extracts from grape pomace obtained from different vinification methods. Food Chemistry, v. 97, n. 1, p. 87-94, 2006.
GRAY, D. A. et al. Antioxidant activity of oat extracts added to human LDL particles and in free radical trapping assays. Journal of Cereal Science, v. 36, n. 2, p. 209-218, 2002.

GUENDEZ, R. et al. An analytical survey of the polyphenols of seeds of varieties of grape (Vitis vinifera sp.) cultivated in Greece: implications for exploitation as a source of value-added phytochemicals. Phytochemical Analysis, v. 16, n. 1, p. 17-23, 2005.

GUENDEZ, R. et al. Determination of low molecular weight polyphenolic constituents in grape (Vitis vinifera sp.) seed extracts: Correlation with antiradical activity. Food Chemistry, v. 89, n. 1, p. 1-9, 2005.

GUO, C. et al. Antioxidant activities of peel, pulp and seed fractions of common fruits as determined by FRAP assay. Nutrition Research, v. 23, n. 12, p. 1719-1726, 2003.

JAYAPRAKASHA, G. K.; SINGH, R. P.; SAKARIAH, K. K. Antioxidant activity of grape seed (Vitis vinifera) extracts on peroxidation models in vitro. Food Chemistry, v. 73, n. 3, p. 285-290, 2001.

JU, Z. Y.; HOWARD, L. R. Effects of Solvent and Temperature on Pressurized Liquid Extraction of Anthocyanins and Total Phenolics from Dried Red Grape Skin. Journal of Agricultural and Food Chemistry, v. 51, n. 18, p. 5207-5213, 2003.

KAMMERER, D. et al. Polyphenol Screening of Pomace from Red and White Grape Varieties (Vitis vinifera L.) by HPLC-DAD-MS/ MS. Journal of Agricultural and Food Chemistry, v. 52, n. 14, p. 4360-4367, 2004.

KAMMERER, D. et al. A novel process for the recovery of polyphenols from grape (Vitis vinifera L.) pomace. Journal of Food Science, v. 70, n. 2, p. 157-163, 2005.

KUSKOSKI, E. M. et al. Actividad antioxidante de pigmentos antociânicos. Ciência e Tecnologia de Alimentos, v. 24, n. 4 , p. 691-693, 2004.

LLOBERA, A.; CAÑELLAS, J. Dietary fibre content and antioxidant activity of Manto Negro red grape (Vitis vinifera): pomace and stem. Food Chemistry, v. 101, n. 2, p. 659-666, 2007.

LOULI, V.; RAGOUSSIS, N.; MAGOULAS, K. Recovery of phenolic antioxidants from wine industry by-products. Bioresource Technology, v. 92, n. 2, p. 201-208, 2004.

LUQUE-RODRÍGUEZ, J. M.; LUQUE DE CASTRO, M. D.; PÉREZ-JUAN, P. Extraction of fatty acids from grape seed by superheated hexane. Talanta, v. 68, n. 1, p. 126-130, 2005.

MAKRIS, D. P.; BOSKOU, G.; ANDRIKOPOULOS, N. K. Polyphenolic content and in vitro antioxidant characteristics of wine industry and other agri-food solid waste extracts. Journal of Food Composition and Analysis, v. 20, n. 2, p. 125-132, 2007.

MANACH, C.; MAZUR, A.; SCALBERT, A. Polyphenols and prevention of cardiovascular diseases. Current Opinion in Lipidology, v. 16, n. 1, p. 77-84, 2005.

MARCO, G. J. A rapid method for evaluation of antioxidants. Journal of the American Oil Chemist's Society, v. 45, p. 594-598, 1968.

MILLER, H. E. A simplified method for the evaluation of antioxidants. Journal of the American Oil Chemist's Society, v. 48, p. 91, 1971.

MOURE, A. et al. Natural antioxidants from residual sources. Food Chemistry, v. 72, n. 2, p. 145-171, 2001.

NEGRO, C.; TOMMASI, L.; MICELI, A. Phenolic compounds and antioxidant activity from red grape marc extracts. Bioresource Technology, v. 87, n. 1, p. 41-44, 2003.

ORAK, H. H. Total antioxidant activities, phenolics, anthocyanins, polyphenoloxidase activities of selected red grape cultivars and 
their correlations. Scientia Horticulturae, v. 111, n. 3, p. 235-241, 2007.

OU, B.; HAMPSCH-WOODILL, M.; PRIOR, R. Development and validation of an improved oxygen radical absorbance capacity assay using fluorescein as the fluorescent probe. Journal of the Agricultural and Food Chemistry, v. 49, n. 10, p. 4619-4626, 2001.

PASTRANA-BONILLA, E. et al. Phenolic Content and Antioxidant Capacity of Muscadine Grapes. Journal of the Agricultural and Food Chemistry, v. 51, n. 18, p. 5497-5503, 2003.

PÉREZ-JIMÉNEZ, J.; SAURA-CALIXTO, F. Effect of solvent and certain food constituents on different antioxidant capacity assays. Food Research International, v. 39, n. 7, p. 791-800, 2006.

PINELO, M. et al. Effect of solvent, temperature, and solvent-to-solid ratio on the total phenolic content and antiradical activity of extracts from different components of grape pomace. Journal of the Agricultural and Food Chemistry, v. 53, n. 6, p. 2111-2117, 2005.

PRIOR, R. L.; WU, X.; SCHAICH, K. Standardized methods for the determination of antioxidant capacity and phenolics in food and dietary supplements. Journal of the Agricultural and Food Chemistry, v. 53, n. 10, p. 4290-4302, 2005.

PULIDO, R.; BRAVO, L.; SAURA-CALIXTO, F. Antioxidant activity of dietary polyphenolics as determined by a modified ferric reducing/ antioxidant power assay. Journal of the Agricultural and Food Chemistry, v. 48, n. 8, p. 3396-3402, 2000.

PUUPPONEN-PIMIÄ, R. et al. Antimicrobial properties of phenolic compounds from berries. Journal of Applied Microbiology, v. 90, n. 4, p. 494-507, 2001.

RE, R. et al. Antioxidant activity applying an improved ABTS radical cation descolorization assay. Free Radical Biological Medicine, v. 26, n. 9, p. 1231-1237, 1999.

RICE-EVANS, C. A.; MILlER, N. J.; PAGANGA, G. Structure antioxidant activity relationships of flavonoids and phenolic acids. Free Radical Biology Medicine, v. 20, n. 7, p. 933-956, 1996.
ROSSI, J. A. J.; SINGLETON, V. L. Colorimetry of total phenolics with phosphomolybdic phosphotungstic acid reagents. American Journal of Enology and Viticulture, v. 16, n. 3, p. 144-158, 1965.

RUBERTO, G. et al. Polyphenol constituents and antioxidant activity of grape pomace extracts from five Sicilian red grape cultivars. Food Chemistry, v. 100, n. 1, p. 203-210, 2007.

SHUI, G.; LEONG, L. P. Residue from star fruit as valuable source for functional food ingredients and antioxidant nutraceuticals. Food Chemistry, v. 97, n. 2, p. 277-284, 2006.

SILVA, S.; MATIAS, A.; NUNES, A. Identification of flavonol glycosides in winemaking by-products by HPLC with different detectors and hyphenated with mass spectrometry. Ciência e Técnica Vitivinícola, v. 20, n. 1, p. 17-33, 2005.

SOUQUET, J. M. et al. Phenolic composition of grape stems. Journal of Agricultural and Food Chemistry, v. 48, n. 4, p. 1076-1080, 2000.

SUN, T.; HO, C. Antioxidant activities of buckwheat extracts. Food Chemistry, v. 90, n. 4, p. 743-749, 2005.

THAIPONG, K. et al. Comparison of ABTS, DPPH, FRAP and ORAC assays for estimating antioxidant activity from guava fruit extracts. Journal of Food Composition and Analysis, v. 19, n. 6-7, p. 669675, 2006

TROIANI, E. P.; TROPIANI, C. T.; CLEMENTE, D. Peroxidase (POD) and Polyphenoloxidase (PPO) in grape (Vitis Vinifera L.). Ciência e Agrotecnologia, v. 27, n. 3, p. 635-642, 2003.

VALDERRAMA, P.; MARANFONI, F.; CLEMENTE, E. Efeito do tratamento térmico sobre a atividade de peroxidase (POD) e polifenoloxidase (PPO) em maçã (Mallus comunis). Ciência e Tecnologia de Alimentos, v. 21, n. 3, p. 321-325, 2001.

YILMAZ, Y.; TOLEDO, R. T. Health aspects of functional grape seed constituents. Trends in Food Science and Technology, v. 15, n. 9, p. 422-433, 2004.

YILMAZ, Y.; TOLEDO, R. T. Oxygen radical absorbance capacities of grape/wine industry byproducts and effect of solvent type on extraction of grape seed polyphenols. Journal of Food Composition and Analysis, v. 19, n. 1, p. 41-48, 2006.

YU, L. et al. Antioxidant properties of hard winter wheat extracts. Food Chemistry, v. 78, n. 4, p. 457-461, 2002. 